\title{
Primer reporte de Mortierella elongata como patógeno del cultivo del aguacate en Michoacán, México
}

\author{
First report of Mortierella elongata as a pathogen of avocado crop \\ in Michoacán, Mexico
}

\begin{abstract}
Anselmo Hernández Pérez ${ }^{1}$, Ernesto Cerna Chávez¹, Juan Carlos Delgado Ortiz², Mariana Beltrán Beache ${ }^{3}$, Omegar Hernández Bautista ${ }^{3}$, Luis Mario Tapia Vargas ${ }^{4}$, Yisa María Ochoa Fuentes ${ }^{1}$

${ }^{1}$ Universidad Autónoma Agraria Antonio Narro, Departamento de Parasitología. Buenavista, Saltillo, CP 35315, Coahuila, México.

${ }^{2}$ CONACYT-Universidad Autónoma Agraria Antonio Narro, Departamento de Parasitología. Buenavista, Saltillo, CP 35315, Coahuila, México. ${ }^{3}$ Culta S.A. de C.V. Boulevard Luis Echeverría Álvarez No. 1700, Col. Altavista, Ciudad Mante, CP 89880, Tamaulipas, México.

${ }^{4}$ INIFAP, Campo Experimental Uruapan. Av. Latinoamericana No. 1101 Col. Revolución, Uruapan, CP 60500, Michoacán, México.
\end{abstract}

\section{RESUMEN}

Antecedentes: Las especies del género Mortierella prosperan usualmente como saprófitas en el suelo y materia orgánica de diversos ecosistemas forestales. Tradicionalmente, se han aislado de los sistemas radicales de diversas especies vegetales. Adicionalmente, investigaciones realizadas en suelo de cultivo de aguacate para lograr la purificación de Pythophthora cinnamomi indican que Mortierella spp. son hongos contaminantes, sin mencionar su patogenicidad.

Objetivo: Esta investigación tuvo como objetivo identificar la presencia de Mortierella sp. y evaluar su posible patogenicidad en el cultivo del aguacate.

Métodos: Las cepas se aislaron de suelo de huertas ubicadas en los principales municipios productores de aguacate en el estado de Michoacán. Las cepas fueron identificadas y se sometieron a pruebas de patogenicidad con plantas de aguacate de tres meses de edad y con plántulas con seis hojas verdaderas.

Resultados y conclusión: Las cepas fueron identificadas morfológica y molecularmente como Mortierella elongata. El fitopatógeno causó síntomas de decaimiento en las partes aéreas de las plántulas de aguacate. Este trabajo entonces demuestra por primera ocasión, que existen cepas del género Mortierella que son patógenas en plántulas de aguacate. Palabras clave: patogenicidad, Persea americana, Zygomycota, Uruapan

\section{ABSTRACT}

Background: Mortierella species usually thrive as saprophytes in the soil and organic matter from diverse forest ecosystems. Traditionally, they have been isolated from the root systems of various plant species. Additionally, research carried out in avocado soil to achieve the purification of Pythophthora cinnamomi consider that Mortierella spp. are microbial non-pathogenic contamination.

Objective: Therefore, this research aimed to identify the presence of Mortierella sp. and to evaluate its possible pathogenicity in avocado crop.

Methods: Strains were isolated from orchard soils of the main avocado producing municipalities in the state of Michoacán. The strains were identified and subjected to pathogenicity tests with three months old avocado plants and with seedlings with six true leaves.

Results and conclusions: The strains were morphologically and molecularly identified as Mortierella elongate. The phytopathogen caused symptoms of decay in the shoots of the avocado seedlings. This work then demonstrates for the first time that there are strains of the genus Mortierella that are pathogenic to avocado seedlings.

Keywords: pathogenicity, Persea americana, Zygomycota, Uruapan

\section{ARTICLE HISTORY}

Received 06 October 2017 / Accepted 18 September 2018

On line 02 November 2018

La producción mundial del cultivo del aguacate es de 5028756 toneladas, siendo el continente americano el principal productor con $68.8 \%$, seguido del continente Africano con 15.9 \% (FAOSTAT, 2013).

\section{CORRESPONDING AUTHOR}

\4isa María Ochoa Fuentes, yisa8a@yahoo.com
México, es el principal país productor y consumidor de aguacate en el mundo, con una superficie de 203 732 ha, $72.5 \%$ de las cuales se encuentran en el estado de Michoacán. La producción nacional es de 1 
878599 toneladas, con rendimientos promedio de 10 ton/ha y un consumo per cápita de $7 \mathrm{Kg}$ (SAGARPA, 2015; SIAP, 2014). Sin embargo, existen diferentes limitantes fitosanitarias, las cuales, reducen significativamente el rendimiento, ocasionan malformaciones del fruto e incluso originan la muerte de los árboles de aguacate. El Oomyceto Phytophthora cinnamomi, causante de la pudrición del sistema radical, es el fitopatógeno de mayor importancia económica (Ploetz et al., 1994; Pérez, 2008). Hasta hace algunos años solo se mencionaba a $P$. cinnamomi como el único patógeno responsable de esta sintomatología. Sin embargo, también existen reportes de fitopatógenos aislados de tejido de raíz de aguacate como: Cylindrocladium parasiticum, Cylindrocarpon liriodendri, Nectria liriodendri, Ilyonectria macrodidyma y Phytopythium vexan; los cuales, logran causar una marchitez generalizada (Dann et al., 2011; Vitale et al., 2012; Rodríguez et al., 2014). El género Mortierella, cuenta con más de 100 especies reportadas (Nagy et al., 2011). Tsao y Guy (1977), en una investigación realizada con suelo de cultivo de aguacate para lograr la purificación de $P$. cinnamomi indicaron que los hongos del género Mortierella son contaminantes sin hacer mención de su patogenicidad. Dichos autores propusieron el uso del hymexasol para su inhibición ya que sin este ingrediente activo logran desarrollarse un gran número de colonias superando significativamente al oomiceto P. cinnamomi. Por lo anterior, esta investigación tuvo como objetivo identificar la presencia del género Mortierella y corroborar su posible patogenicidad en el cultivo del aguacate (Persea americana Mill., variedad "Hass").

En los meses de agosto y septiembre de 2014, se recolectaron muestras de raíces en árboles de aguacate que presentaban la sintomatología característica de muerte descendente conocida como tristeza del aguacate. El muestreo se efectuó en la zona de goteo y se realizó en 40 huertos de los municipios de Uruapan, Peribán, Tancítaro y San Juan Nuevo Parangaricutiro, en el estado de Michoacán, México. El aislamiento consistió en eliminar el exceso de suelo de las raíces con agua corriente, se realizaron cortes longitudinales menores a $0.5 \mathrm{~cm}$ de la zona infectada. Solo se seleccionaron raíces que presentaban coloración café obscuro y consistencia quebradiza. Los fragmentos fueron desinfectados con solución de hipoclorito de sodio a 3 \% durante 3 minutos, seguido de 3 lava- dos de agua destilada estéril y sembrados en placas de Petri con medio V8 ${ }^{\circledR}$-PARPH (Davison y Ribeiro, 1996). Las placas se incubaron a $28{ }^{\circ} \mathrm{C}$ por 3 días. La purificación se realizó por la técnica de punta de hifa, transfiriéndose a cajas Petri con medio de cultivo V $8^{{ }_{-}}{ }_{-}$ agar, donde crecieron como aislamiento puro, posteriormente la identificación morfológica se efectuó con las claves de identificación de Gams (1977). Para la identificación molecular, se utilizó la técnica PCR-ITS; de las cepas aisladas se extrajo ADN, a partir de 0.2 $\mathrm{g}$ de micelio del cultivo puro, de acuerdo a la metodología de Doyle y Doyle (1990). Para la amplificación de la region ITS se emplearon los iniciadores ITS1 (5'TCCGTAGGTGAACCTGCGG-3') e ITS4 (5'- TCCTCCGCTTATTGATATGC-3’). Se visualizó el producto de la reacción por medio de electroforesis en gel de agarosa a $2 \%$. Este se tiñó con GelRed (GenScript $\left.{ }^{\circledR}\right)$, se visualizó en un transiluminador; y los productos de PCR se secuenciaron. Las pruebas de patogenicidad se realizaron mediante dos técnicas de inoculación, la primera con plantas de aguacate de 3 meses de emergencia y la segunda con plántulas que presentaban 6 hojas verdaderas. La técnica de inoculación para las plantas de 3 meses de emergencia consistió en la maceración del micelio extraído de 5 cajas Petri de cada cepa (5). Posteriormente se realizó el conteo con apoyo de un hemacitómetro; se inocularon 3 plantas por tratamiento en la base del tallo, con 250 $\mathrm{mL}$ del macerado a una concentración de $1 \times 10^{6}$ de propágulos infectivos (Ochoa et al., 2015). Para las plántulas de 6 hojas verdaderas se realizó una adaptación de la técnica descrita por Engelbrecht y Berg (2013) y Van den Berg et al. (2007), la cual consistió en pesar 500 mg de micelio de las cepas en estudio, el cual fue fraccionado mediante agitación forzada durante 5 minutos en $150 \mathrm{~mL}$ de agua destilada estéril, de éste se tomaron alícuotas de $50 \mathrm{~mL}$ y se colocaron en frascos de cristal previamente esterilizados que contenían $100 \mathrm{~mL}$ de agua destilada estéril, las raíces de las plántulas fueron lavadas con agua destilada estéril para eliminar los residuos del sustrato. Una vez limpias, fueron introducidas en frascos que contenía la solución de Mortierella sp., colocando una planta por frasco. Dichos unidades fueron mantenidas en una cámara bioclimática a $23{ }^{\circ} \mathrm{C}$. Adicionalmente, se utilizaron 3 testigos tratados con agua destilada estéril y al término de la evaluación se recuperó el patógeno en los medios descritos previamente. 
Las cepas aisladas se identificaron hasta especie, observándose hifas hialinas y septadas, clamidosporas de pared gruesa, esporangios terminales, crecimiento rápido de $1.65 \mathrm{~cm}$ por día y al llenar las cajas Petri se observó una macromorfología colonial en forma arrosetada. Dichas características coincidieron con las reportadas por Gams (1977) y Tsuneo (2010) para Mortierella. La secuencia obtenida se alineo con la base de datos del Banco de Genes del National Center for Biotechnology Information (NCBI) de EUA (www.ncbi.nlm. nih.gov/), dando como resultado desde un $97 \%$ hasta un $99 \%$ de similitud con Mortierella elongata (Tabla 1).

TABLA 1. Caracterización molecular de los aislamientos de las secuencias reportadas en el banco de genes con las secuencias intergénicas (ITS ) de los genes rDNA

\begin{tabular}{cccc}
\hline CEPA & ESPECIE & NO. DE ACESSO & IS \\
\hline 1 & Mortierella elongata & KU574262.1 & $99 \%$ \\
2 & Mortierella elongata & FJ161928.1 & $98 \%$ \\
3 & Mortierella elongata & FJ161928.1 & $97 \%$ \\
4 & Mortierella elongata & FJ161928.1 & $97 \%$ \\
5 & Mortierella elongata & FJ161921.1 & $97 \%$ \\
\hline
\end{tabular}

La prueba de patogenicidad de las plantas inoculadas presentaron decaimiento en la parte apical, seguido de una marchitez generalizada en hojas y tallo. Mientras que las plantas no inoculadas no presentaron ninguna sintomatología. Se tiene conocimiento que el género Mortierella es un habitante endémico de bosque, se encuentra presente como saprófito en diferentes ecosistemas y regiones del mundo. Diversos autores han señalado que se ha logrado aislar del sistema radical de diversas especies de plantas pero no existe información de su carácter patológico (Lumley et al., 2001; Yadav et al., 2014; Bonito et al., 2014 y Uehling et al., 2017). A la fecha este es el primer reporte de una especie del género Mortierella como agente causal en plántulas de aguacate. Sin embargo, es necesario continuar con la evaluación de la patogenicidad de diferentes cepas en plantas jóvenes de aguacate y realizar un estudio de la interacción que presenta dicho hongo con otros fitopatógenos de raíz.

\section{LITERATURA CITADA}

Bonito, G., H. Reynolds, M.S. Robeson, J. Nelson, B.P. Hodkinson, G. Tuskan, C.W. Schadt, R. Vilgalys, 2014. Plant host and soil origin influence fungal and bacterial assemblages in the roots of woody plants. Molecular Ecology 23: 3356-3370.

Dann, E., L. Forsberg, A. Cooke, K. Pegg, R. Shivas, Y. Tan, 2011. The "Cylindro" complex of avocado root pathogens. VII World Avocado Congress. Cairns, Australia. Pp. 1-12.

Doyle, J., J.L. Doyle, 1990. Isolation of plant DNA from fresh tissue. Focus 12: 13-15.

Engelbrecht, J., N. Berg, 2013. Expression of defence-related genes against Phytophthora cinnamomi in five avocado rootstocks. South African Journal of Science 109: 1-8.

Davison, E., O. Ribeiro, 1996. Phytophthora diseases worldwide. American Phytopathological Society Press, Minnesota. Pp. 269280.

FAOSTAT, 2013. Food and Agriculture Organization of the United Nations. Database consulted on January 2017: http://faostat3. fao.org/browse/Q/QC/S

Gams, W., 1977. A key to the species of Mortierella. Persoonia 9: 381-391.

Lumley, T., D. Gignac, R. Currah, 2001. Microfungus communities of white spruce and trembling aspen logs at different stages of decay in disturbed and undisturbed sites in the boreal mixedwood region of Alberta. Canadian Journal of Botany 79: 76-92.

Nagy, L., T. Petkovits, G.M. Kovacs, K. Voigt, C. Vagvolgyi, T. Papp, 2011. Where is the unseen fungal diversity hidden. A study of Mortierella reveals a large contribution of reference collections to the identification of fungal environmental sequences. New Phytologist 191: 789-794.

Ochoa, Y.M., E. Cerna, G. Gallegos, M. Cepeda, J. Landeros, A. Flores, 2015. Variabilidad patogénica de Phytophthora cinnamomi Rands en Persea americana Mill. de Michoacán, México. Ecosistemas y Recursos Agropecuarios 2(5): 211-215.

Pérez, R.M., 2008. Significant Avocado Diseasses Caused by Fungi and oomycetes. The European Journal of Plant Science and Biotechnology 2(1): 1-24.

Ploetz, R., G. Zentmyer, W. Nishijima, k. Rohrbach, H. Ohr, 1994. Compendium of tropical fruit diseases. APS Press, Minnesota.

Rodríguez-Padrón, C., A. Rodríguez, F. Silverio, 2014. Patogenicidad en aguacate de aislados locales de especies de Phytophthora y Phytopythium. Primera descripción de Phytophthora niederhauserii como patógeno del aguacate. XVII Congreso de la Sociedad Española de Fitopatología. Lleida, España. Pp. 130.

SAGARPA, 2015. Secretaria de Agricultura, Ganadería, Desarrollo Social, Pesca y Alimentación. Sistema de Información agroalimentaria y pesquera. Boletín Informativo. http://www.siap.sagarpa.gob.mx. Fecha de consulta abril del 2017.

SIAP, 2014. Sistema de Agroalimentaria y Pesquera. Anuario Estadístico de la Producción Agrícola. http://www.siap.gob.mx. Fecha de consulta abril del 2017.

Tsao, P., S. Guy, 1977. Inhibition of Mortierella and Pythium in a Phytophthora-isolation médium containing Hymexazol. Phytopathology 67: 796-801.

Tsuneo, W., 2010. Pictorial atlas of soil and seed fungi: Morphologies of cultural fungi and key to species. Third edition. CRC Press, Florida.

Uehling, J., A. Gryganskyi, K. Hameed, T. Tschaplinski, P.K. Misztal, S. Wu, A. Desirò, N. Vande Pol, Z. Du, A. Zienkiewicz, K. 
Zienkiewicz, E. Morin, E. Tisserant, R. Splivallo, M. Hainaut, B. Henrissat, R. Ohm, A. Kuo, J. Yan, A. Lipzen, M. Nolan, K. LaButti, K. Barry, A.H. Goldstein, J. Labbé, C. Schadt, G. Tuskan, I. Grigoriev, F. Martin, R. Vilgalys, G. Bonito, 2017. Comparative genomics of Mortierella elongata and its bacterial endosymbiont Mycoavidus cysteinexigens. Environmental Microbiology 19: 2964-2983.

Van den Berg, N., D.K. Berger, I. Hein, P. Birch, M.J. Wingfield, A. Viljoen, 2007. Tolerance in banana to Fusarium wilt is associated with early up-regulation of cell wall-strengthening genes in the roots. Molecular Plant Pathology 8: 333-341.
Vitale, A., D. Aiello, V. Guarnaccia, G. Perrone, G. Stea, G. Polizzi, 2012. First Report of Root Rot Caused by llyonectria (=Neonectria) macrodidyma on avocado (Persea americana). Journal of Phytopathology 160: 156-159.

Yadav, D.R., S.W. Kim, A.G. Babu, M. Adhikari, C. Kim, H.B. Lee, Y.S. Lee, 2014. First report of Mortierella alpina (Mortierellaceae, Zygomycota) isolated from crop field soil in Korea. Mycobiology 42(4): 401-404. 